\title{
PRESENTACIÓN DE REVISTAS
}

\section{REVISTA DE FÍSICA}

És una publicació pertòdica de la Societat Catalana de Física (Filial de I'Institut d'Estudis Catalans) que està concebuda com una revista d'alta divulgació de temes que, bàsicament, interessen als professionals de la Física. Està, per tant, dirigida bàsicament a Ilicenciats en Física de qualsevol especialitat que llegeixin el català.

Atenent els seus destinataris, els articles que inclou tenen en compte el bagatge científico-cultural que es pot suposar comú a tots ells, és a dir, l'equivalent als tres primers cursos de la licenciatura. Això fa que Revista de Física tingui tambécom a lectors potencials estudiants de segon cicle de Física.

Atès que és criteri de Revista de Física subscriure convenis de col.laboració i intercanvi amb altres publicacions d'objectius i plantejaments similars, és possible que, en el cas de disposar dels permisos corresponents dels autors, la revista reprodueixi articles prèviament apareguts en altres revistes i, recíprocament, articles publicats a Revista de Fisica siguin reproduïts i difosos posteriorment a través d'altres publicacions similars.

Revista de Física té, des del seu inici, una periodicitat semestral, i fins ara ha publicat tres números. El quart és previst que surti el mes d'abril de 1993. Cada número inclou, a més d'altres aportacions de menor extensió, un treball de posada al dia sobre un tema determinat, per la seva actualitat o per l'interès qui se.li pressuposa, un parell d'articles exposant líntes de trebali de recerca en física, un article sobre aspectes relacionats amb l'ampli espectre d'activitats professionals dels fúsics en el món productiu i de serveis, un article sobre aspectes metodologics o didàctics, bàsicament referits a l'ensenyament secundari de la Física, una col-laboració d'estudiants de segon cicle de la llicenciatura i un article sobre experimentació assistida per ordinador.

Els interessats a subscriure-s'hi ho poden fer adreçant-se a:

Revista de Física, Societat Catalana de Física (Institut d'Estudis Catalans). Departament de Publicacions. C/ Carme, 47. 08001 Barcelona.

El pretu de la subscripció anual és de 1.000 ptes. i equival a dos números de la revista.

\section{PUBLICACIONES RECIBIDAS}

\section{CONSUMO E RESIDUOS SÓLIDOS URBANOS}

EI grupo Gaia de Educación Ambiental ha elaborado esta unidad didáctica como parte del proyecto curricular A Natureza nacidade que pretende desarrollarel Diseño Curricular Base de Educación Secundaria Obligatoria en el área de Ciencias de la Naturaleza.

Experimentada desde el curso 1988-89, ha sufrido diversas modificaciones e incorporaciones hasta llegar a la versión actual.

Consta de dos partes claramente diferenciadas: una dirigida al profesorado, en la que se justifica la propuesta de esta unidad y se explicitan los objetivos, contenidos, propuestas de evaluación de la unidad y se dan orientaciones didácticas para la puesta en práctica de las actividades; y otra en la que a la vez que se explicita la organización y secuencia- ción de las actividades de aprendizaje, se dan indicaciones a los alumnos.

La publicación, de carácter gratuito, puede solicitarse a:

Area de Educación e Xuventude. Concello de Ourense. Casa do Concello. Praza Maior s/n. 32005 Ourense. Tel. (988) 388131 .

ACTAS DEL CONGRESO INTERNACIONAL DE HISTORIA DE LAS CIENCIAS FÍSICO-MATEMÁTICAS Y ENSEÑANZA DE LAS CIENCIAS

El grupo Interdivisional de Historia de la Física de la Sociedad Europea de Física en colaboración con el Departamento de Didáctica de las Ciencias Experimentales de la Universidad Complutense de Madrid organizaron el pasado mes de septiembre el Congreso Internacional de
«Historia de las Ciencias Fisico-Matemáticas y Enseñanza de las Ciencias».

Este Congreso, dirigido a estudiantes, profesores e investigadores interesados en la historia de la ciencia, la enseñanza de las ciencias físico-matemáticas y la formación del profesorado forma parte de una serie de encuentros internacionales celebrados en Pavía (1983), Munich (1986), París (1988) y Cambridge (1990).

Las actas del Congreso, de muy reciente aparición, pueden solicitarse contrarreembolso, al precio de 1000 ptas. más gastos de envío, a:

\section{Antonio Moreno González}

Departamento de Didáctica de las Ciencias Experimentales

Escuela Universitaria de Formación de Profesorado «María Díaz Jiménez». Av. Filipinas, 3. 28003. Madrid. 